\title{
Tax Interdependence in American States
}

\author{
Claudio A. Agostini *†
}

\begin{abstract}
State governments finance their expenditures with multiple tax instruments, so when collections from one source decline, they are typically compensated by greater revenues from other sources. This paper addresses the important question of the extent to which personal and corporate income taxes are used to compensate for sales tax fluctuations within the U.S. states. The results show that one percent increase in the sales tax rate is associated with a half and a third percent decrease in the personal and corporate income tax rates respectively. In terms of tax revenues per capita, the results show that a one percent increase in the sales tax revenue per capita is associated with a 3 percent and a 0.9 percent decrease in the corporate and personal income tax revenue per capita respectively.
\end{abstract}

JEL: H71, H21

Keywords: Tax Mix, State Taxes, Instrumental Variables.

\section{Introduction}

In the real world we observe countries and states imposing taxes simultaneously on consumption, personal income and corporate income. The literature has successfully developed theoretical models to explain why governments use many taxes and mix them differently (Boadway, Marchand, and

\footnotetext{
${ }^{*}$ Department of Economics, University of Michigan, Ann Arbor (Email: cagostin@umich.edu)

${ }^{\dagger}$ I am grateful to Jim Hines for all his valuable comments, support and encouragement throughout this project. All the remaining errors are mine.
} 
Pestieu (1994), Cremer, Pestieu, and Rochet (2001), Gentry and Ladd (1994), Gordon and MacKieMason (1994), Gordon and Nielsen (1997), Harmon and Mallick (1994), White (1983)). Empirically, an important effort has been devoted to explain the determinants of tax structures, specifically, the economic, administrative and political reasons that lead to the choice of different tax policies. There is one strand of the literature, for example, that has investigated the tax spillovers from one jurisdiction to another and/or the degree of tax competition among different jurisdictions (Brett and Pinske (2000), Buettner (2001), Büttner (1999), Heyndels and Vuchelen (1998), Ladd (1992), Rork (2001)). However, this line of work has only been used to explore the effects of a change in a specific tax in jurisdiction $i$ on the same specific tax on jurisdiction $j$ (the effect of the change in the sales tax rate in Connecticut on the sales tax rate in New York, for example). A different question is how a change in one specific tax affects the other taxes within the same jurisdiction. If we follow the story of the tax competition literature, we can see how these two different questions are closely related. If one jurisdiction changes one of its tax rates, the competing (neighboring) jurisdiction will change its tax rate, on the same tax, as a response. The magnitude and sign of this response has been extensively investigated by the empirical work of this strand of the literature. However, this is not the end of the story. After the competing jurisdiction has changed its tax rate it may still need to adjust its other tax rates, especially if it wants to keep total tax revenue constant. As a result, the competing jurisdiction will have not only a different tax rate on the same type of tax the first jurisdiction changed, but it will also have a different tax mix than before.

State governments use multiple taxes to finance their expenditures, and even in the case in which there is no tax competition among jurisdictions, they do face some exogenous shocks that might affect the collections from one of these taxes. If the state governments want to keep providing 
Figure 1:

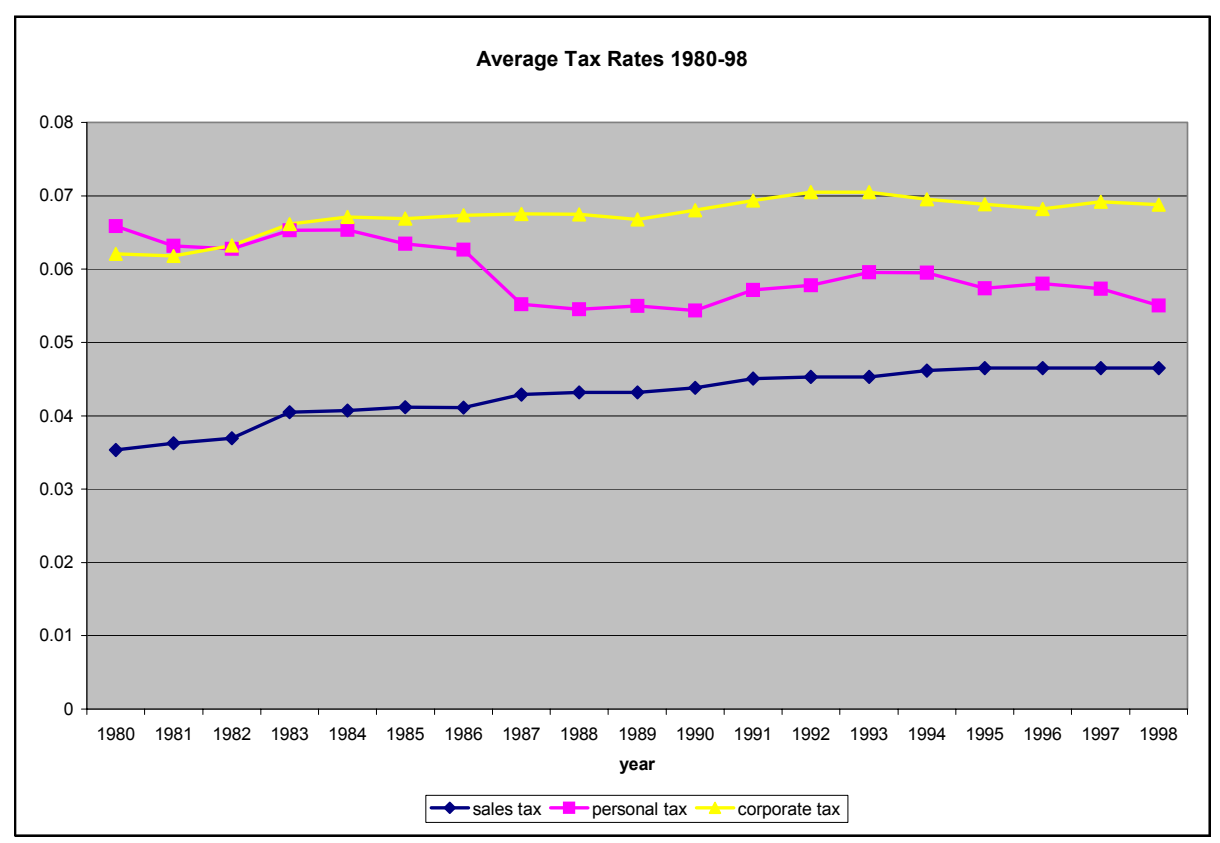

the same level of public goods and services as before, they must compensate the effects of these shocks changing the revenue collected from other taxes. In this paper I use panel data for the 50 U.S. states to investigate the effects of a change in sales taxes on corporate and personal income taxes within a state. One of the problems a researcher usually faces when doing empirical work with taxes is that governments change taxes rather infrequently. One of the advantages of using state taxes is not only that they provide good cross-sectional variation, but also that there is more variation over time because states do modify taxes more often than countries. Furthermore, in the case of the U.S. states the tax mix they use has been changing quite significantly during the last 20 years.

Figure 1 shows the average state tax rates during the period 1980-1998 for the three main taxes 
used by the U.S. state. As can be seen from the figure, the average tax mix of the U.S. states has been changing over time. The sales tax rate and the top statutory corporate tax rate has been slowly increasing and the top statutory personal income tax rate has been decreasing, even though it has fluctuated more. If the tax revenue per capita collected from different sources is considered, which somehow includes the base of the taxes too, the trend is somewhat different and provides a complementary story to the tax rates mix. Figure 2 shows the average state tax revenues per capita during the period 1980-1998. The revenue per capita collected from corporate income taxes decreased by around one third during the early 80 s and has been almost constant since then, even if the average statutory tax rate has been slowly increasing. The revenue per capita collected from personal income and sales taxes has been steadily increasing during this period, the latter more than the former, even though the average personal tax rate has decreased and the sales tax rate has been steadily increasing. ${ }^{1}$

Obviously, these figures show just averages and not too many conclusions can be drawn from them, but they show that the average state tax mix has been changing over time and exploring the interdependence of different taxes within the tax mix is the goal of this paper.

The paper continues as follows. Section 2.2 considers the optimal tax problem of a state government when three different taxes can be used and one of them can be imposed on goods that are also consumed by foreign citizens. Section 2.3 describes the data used in the empirical analysis. Section 2.4 shows and interprets the empirical results, and Section 2.5 concludes.

\footnotetext{
${ }^{1} \mathrm{~A}$ similar figure for fractions of tax revenues from different sources is reported in the appendix.
} 
Figure 2:

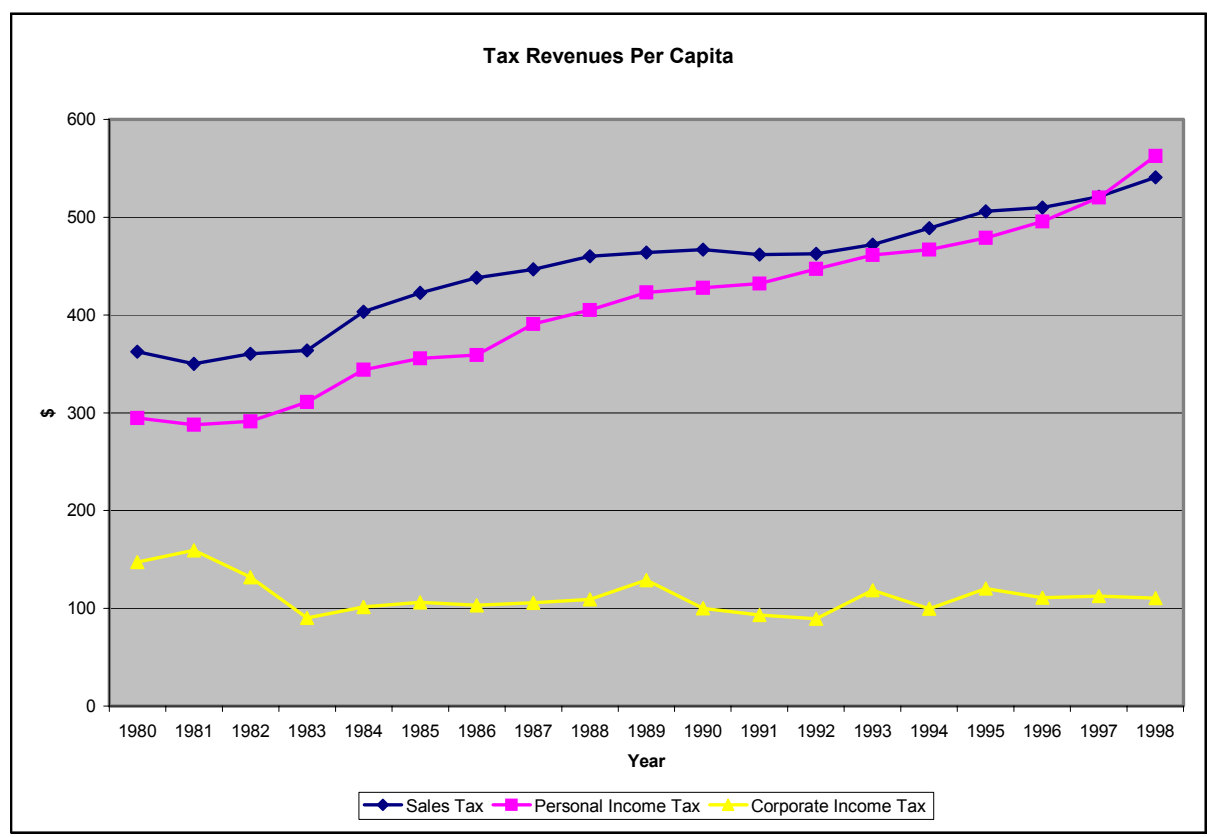

\section{The State Government Optimal Tax Problem}

In the section I use a standard optimal commodity tax model with the purpose of understanding how different taxes are interrelated and how the tax mix is affected when there is an exogenous shock that affects directly one of the taxes used. Even though a commodity tax model is just an approximation to the actual taxes that American states use, it can provide qualitative lessons that allow a better understanding of the empirical results of this paper.

Following the optimal commodity tax literature (Diamond and Mirrlees (1971), Atkinson and Stiglitz (1972), Auerbach (1985)), we can consider a state in which all consumers are identical, they have no exogenous income and take consumer prices $p$ for the $n+1$ available goods as given. The producer prices $q$ are assumed fixed and the good zero is a numeraire with price $p_{0}=1$. The 
government may use excise taxes on $n$ goods to raise a fixed required revenue $R$.

The state government's problem is then to maximize the utility of the representative consumer subject to its revenue constraint and the consumer conditions for utility maximization. This maximization problem can be written as:

$$
\begin{gathered}
\max _{p} V(p) \\
\text { s.t. } \\
t x \geq R
\end{gathered}
$$

The Lagrangian and the first order conditions of this problem are:

$$
\begin{gathered}
L=V(p)-\mu[R-t x] \\
\frac{\partial V}{\partial p_{i}}+\mu\left[\sum_{j} t_{j} \frac{\partial x_{j}}{\partial p_{i}}+x_{i}\right]=0 \quad \forall i
\end{gathered}
$$

Using the envelope theorem to substitute $\frac{\partial V}{\partial p_{i}}$ for $-\lambda x_{i}$ (where $\lambda$ is the consumer's marginal utility of income), the Slutsky equation, and defining:

$$
\alpha=\lambda+\mu \sum_{j} t_{j} \frac{\partial x_{j}}{\partial y}
$$


as the marginal social utility of income (Diamond (1975)), equation (4) can be rewritten as:

$$
-\sum s_{j i} t_{j}=\left(\frac{\mu-\alpha}{\mu}\right) x_{i} \quad \forall i
$$

these $n$ first order conditions can be stacked to have the following system of equations:

$$
S t=-\left(\frac{\mu-\alpha}{\mu}\right) x
$$

where $S$ is the Slutsky matrix excluding good zero. Now, the optimal taxes can be obtained by inverting the Slutsky matrix and multiplying both sides of (7) by $S^{-1}$ :

$$
t^{*}=-\left(\frac{\mu-\alpha}{\mu}\right) S^{-1} x
$$

If it is assumed that the matrix $S$ is diagonal (all cross-effects are zero), the Ramsey inverse elasticity rule is obtained:

$$
t_{i} \sim \frac{p_{i}}{\varepsilon_{i i}}
$$

where $\varepsilon_{i i}=s_{i i}\left(p_{i} / x_{i}\right)$ are compensated own-price elasticities. Under this assumption, the choice of the untaxed good might be quite relevant, because it may be more reasonable to assume no cross effects among taxed goods when labor is the numeraire than when another good is. As pointed out by Auerbach (op. cit.), labor (or minus leisure) is usually chosen as a numeraire in most of the models but this does not imply that the government cannot tax labor ${ }^{2}$. We know that

\footnotetext{
${ }^{2}$ Some authors choose leisure as the numeraire claiming the inability of the government to tax leisure, but as Auerbach (op. cit.) states : "[the government] can tax leisure purchases (labor supply)".
} 
state governments do actually tax labor income, and the most common untaxed goods are usually the goods considered "necessities" (food, medicines and clothes). Consider then the case of four goods, where the three taxed goods are labor, consumption and capital, and the numeraire is the consumption of necessities. This is a case in which the zero cross effects assumption might not be a reasonable one, especially between labor and consumption, and, therefore, the optimal taxes are better characterized by the system of equations (8) with at least $s_{12}=s_{21} \neq 0 .^{3}$

The analysis up to this point is basically the standard optimal tax theory with a different choice of the numeraire good. Let's consider now two different aspects of the problem. First, I will introduce consumption by foreign citizens. In an open economy, even if the state governments want to maximize the utility of their own citizens, several goods might be bought and consumed by people who live in a different state $^{4}$ and this should affect the optimal taxes. Why is the consumption of foreign citizens relevant? Recall that this paper is about tax interdependence and the main goal is to estimate the effects of a change in a state sales tax on the other taxes within the same state. However, all state taxes are set simultaneously and instrumental variables are needed to consistently estimate these effects. In this context, the role of foreign consumption is just the role of an instrumental variable that allows to identify the coefficient of endogenous explanatory variables. Second, I will consider the optimal solution in terms of revenues instead of tax rates. The main reason for this, is that state governments can actually change not only tax rates, but also tax bases. The relevant parameter that states may consider then, when setting their tax policies,

\footnotetext{
${ }^{3}$ The three main taxes used by the U.S. states are sales, personal income, and corporate income. The use of an optimal commodity tax framework might not be the most appropriate for corporate income taxes, but the goal of the paper is to show and estimate the interdependence of different state taxes and this model must be understood, as in Mirrlees (1975), just as an approximation.

${ }^{4}$ We can think of tourism or cross-border shopping as the main reason for this to happen.
} 
is the fraction of revenue or the revenue per capita they collect from each different tax.

Considering again the case where the three taxed goods are labor, consumption and capital, and the numeraire is the consumption of necessities, where, now, consumption goods can be bought also by consumers from out of the state. The state government problem can be written as:

$$
\begin{gathered}
\max _{t_{1}, t_{2}, t_{3}} V\left(p_{1}, p_{2}, p_{3}\right) \\
\text { s.t. } \\
t_{1}\left(x_{1}+x_{1}^{f}\right)+t_{2} x_{2}+t_{3} x_{3} \geq R
\end{gathered}
$$

where $x_{1}$ and $x_{1}^{f}$ are quantities of good one purchased by domestic and foreign residents respectively. Defining $\gamma \equiv \frac{x_{1}^{f}}{x_{1}^{f}+x_{1}}$, the fraction of good 1 purchases by foreign citizens, this problem can be rewritten as:

$$
\begin{gathered}
\max _{t_{1}, t_{2}, t_{3}} V\left(p_{1}, p_{2}, p_{3}\right) \\
\text { s.t. } \\
t_{1} \frac{x_{1}}{(1-\gamma)}+t_{2} x_{2}+t_{3} x_{3} \geq R
\end{gathered}
$$

The Lagrangian of this problem and the first order conditions characterizing internal choices of $\mathrm{t}_{1}, \mathrm{t}_{2}$, and $\mathrm{t}_{3}$ are:

$$
L=V\left(p_{1}, p_{2}, p_{3}\right)-\mu\left[R-t_{1} \frac{x_{1}}{(1-\gamma)}-t_{2} x_{2}-t_{3} x_{3}\right]
$$




$$
\begin{gathered}
\frac{\partial V}{\partial p_{1}}+\mu\left[\frac{t_{1}}{(1-\gamma)} \frac{\partial x_{1}}{\partial p_{1}}+\sum_{j=2,3} t_{j} \frac{\partial x_{j}}{\partial p_{1}}+\frac{x_{1}}{(1-\gamma)}\right]=0 \\
\frac{\partial V}{\partial p_{i}}+\mu\left[\frac{t_{1}}{(1-\gamma)} \frac{\partial x_{1}}{\partial p_{i}}+\sum_{j=2,3} t_{j} \frac{\partial x_{j}}{\partial p_{i}}+x_{i}\right]=0 \quad \text { for } i=2,3
\end{gathered}
$$

Using the Slutsky equation, the envelope theorem to substitute $\frac{\partial V}{\partial p_{i}}$ for $-\lambda x_{i}$ (where $\lambda$ is the consumer's marginal utility of income), and defining:

$$
\alpha=\lambda+\mu\left[\frac{t_{1}}{(1-\gamma)} \frac{\partial x_{1}}{\partial y}+\sum_{j=2,3} t_{j} \frac{\partial x_{j}}{\partial y}\right]
$$

as a modified marginal social utility of income, equations (13) and (14) can be rewritten as:

$$
\begin{gathered}
-\frac{s_{11} t_{1}}{(1-\gamma)}-\sum_{j=2,3} s_{j 1} t_{j}=\left(\frac{\mu-\alpha(1-\gamma)}{\mu(1-\gamma)}\right) x_{1} \\
-\frac{s_{1 i} t_{1}}{(1-\gamma)}-\sum_{j=2,3} s_{j i} t_{j}=\left(\frac{\mu-\alpha}{\mu}\right) x_{i} \quad \text { for } i=2,3
\end{gathered}
$$

The left-hand side of these equations can be interpreted as the compensated change in the demand for good $i$, meaning a change in the demand for good $i$ that would result if the consumer were compensated to stay in the same indifference curve (and $s_{i j}$ were constant). ${ }^{5}$ In this particular case the compensated change in the demand for good 1 is adjusted by $1 /(1-\gamma)$ to take into account the effect of foreign demand for good 1. For interpreting the right-hand side, it is important to recall why the consumer's marginal utility of income, $\lambda$, differs from the social marginal utility of income, $\alpha$. The reason is that an additional dollar given to the consumer increases his utility in

\footnotetext{
${ }^{5}$ Samuelson ( 1951).
} 
two ways: a direct effect captured by $\lambda$ (the consumer has more income to spend) and an indirect effect captured by the second term in $\alpha$ (the additional expenditure increases revenue). As usual, $\mu$ represents the shadow cost (in terms of utility) of raising an additional dollar of revenue and, therefore, the term $(\mu-\alpha)$ measures the marginal excess burden of the tax, the benefit of switching from optimal indirect taxes to lump-sum taxes. In general, if revenue is positive, $(\mu-\alpha) \geq 0 .{ }^{6},{ }^{7}$ When $\gamma=0$, the optimal solution suggests setting taxes in such a way that an equiproportional reduction in the demand for all goods is attained. When $\gamma>0$, the optimal solution implies a higher proportion in the demand reduction of good 1.

In the case of good 1, the first order condition show that the marginal excess burden per dollar of revenue raised is $(\mu-\alpha(1-\gamma)) / \mu(1-\gamma)$, which is greater than $(\mu-\alpha) / \mu$, the marginal excess burden from taxing goods 2 and 3 . The intuition behind this result is very simple, a fraction of the excess burden imposed by taxing good 1 is borne by foreign consumers and, therefore, the government should tax good 1 proportionally more than goods 2 and 3.

The three first order conditions can be stacked to have the following system of equations:

$$
\widetilde{S} t=-M x
$$

where $\widetilde{S}$ is a modified Slutsky matrix excluding good zero (necessities), $t$ is the tax vector, $M$ is a diagonal matrix, and $x$ is the commodity vector. ${ }^{8}$ Again, the optimal taxes can be obtained

\footnotetext{
${ }^{6}$ The Slutsky matrix is negative semidefinite. Using this property it can be shown that $\frac{\mu-\alpha}{\mu} \geq 0$ and $\frac{\mu-\alpha(1-\gamma)}{\mu(1-\gamma)} \geq 0$ when revenue is positive.

${ }^{7}$ Additionally, if revenue is nondecreasing in income, $\mu \geq \lambda$.

${ }^{8} \widetilde{S}=\left[\begin{array}{ccc}\frac{s_{11}}{(1-\gamma)} & s_{21} & s_{31} \\ \frac{s_{12}}{(1-\gamma)} & s_{22} & s_{32} \\ \frac{s_{13}}{(1-\gamma)} & s_{23} & s_{33}\end{array}\right], M=\left[\begin{array}{ccc}\frac{\mu-\alpha(1-\gamma)}{\mu(1-\gamma)} & 0 & 0 \\ 0 & \frac{\mu-\alpha}{\mu} & 0 \\ 0 & 0 & \frac{\mu-\alpha}{\mu}\end{array}\right]$
} 
by inverting the modified Slutsky matrix and multiplying both sides of (17) by $\widetilde{S}^{-1}$ :

$$
t^{*}=-\widetilde{S}^{-1} M x
$$

Assuming that only cross-effects with respect to good 3 are zero (a similar but weaker assumption than the one made to obtain the Ramsey inverse elasticity rule), we have: ${ }^{9}$

$$
\widetilde{S}^{-1}=\left[\begin{array}{ccc}
\frac{s_{22}(1-\gamma)}{s_{11} s_{22}-s_{21} s_{12}} & \frac{-s_{12}}{s_{11} s_{22}-s_{21} s_{12}} & 0 \\
\frac{-s_{21}(1-\gamma)}{s_{11} s_{22}-s_{21} s_{12}} & \frac{s_{11}}{s_{11} s_{22}-s_{21} s_{12}} & 0 \\
0 & 0 & \frac{1}{s_{33}}
\end{array}\right]
$$

and

$$
t^{*}=-\left[\begin{array}{c}
-\frac{[\mu-\alpha(1-\gamma)] s_{22} x_{1}}{\mu\left(s_{11} s_{22}-s_{21} s_{12}\right)}+\frac{(\mu-\alpha) s_{12} x_{2}}{\mu\left(s_{11} s_{22}-s_{21} s_{12}\right)} \\
\frac{[\mu-\alpha(1-\gamma)] s_{21} x_{1}}{\mu\left(s_{11} s_{22}-s_{21} s_{12}\right)}-\frac{(\mu-\alpha) s_{11} x_{2}}{\mu\left(s_{11} s_{22}-s_{21} s_{12}\right)} \\
\frac{(\mu-\alpha) x_{3}}{\mu s_{33}}
\end{array}\right]
$$

Obviously, in the case in which $s_{12}=s_{21}=0$ and $\gamma=0$ we get the Ramsey inverse elasticity rule as the optimal solution (equations (9a)). If we keep the zero cross-effects assumption but $\gamma>0$ the solution is the same as before for $t_{2}$ and $t_{3}$, but the proportionality factor of $t_{1}$ is bigger. In the extreme case in which $\gamma=1$, the optimal $t_{1}$ is not proportional but equal to $\frac{p_{1}}{\varepsilon_{11}}$, which is the highest point on the Laffer curve for that tax. Therefore, under the no cross-effects assumption a higher level of $\gamma$ implies a higher tax on good 1 .

\footnotetext{
${ }^{9}$ In this case the matrix $\tilde{S}$ becomes: $\widetilde{S}=\left[\begin{array}{ccc}\frac{s_{11}}{(1-\gamma)} & s_{21} & 0 \\ \frac{s_{12}}{(1-\gamma)} & s_{22} & 0 \\ 0 & 0 & s_{33}\end{array}\right]$
} 
Now, going back to the case in which $s_{12}=s_{21} \neq 0$, we can see from the solution that a change in $\gamma$ has a direct effect on the optimal tax for goods 1 and 2 and an indirect effect, through $\mu$ and $\alpha$, on the optimal taxes of all goods. The direct effect of $\gamma$ on tax 1 implies that $t_{1}$ is an increasing function of $\gamma$. This effect means that if $\gamma$ increases and $\mu, \alpha$, and $s_{i j}$ remain constant, then the optimal $t_{1}$ will increase. The intuition, again, is that if a bigger fraction of the excess burden of the tax is borne by foreigners then the government can raise the same revenue as before imposing a higher burden on good 1. The direct effect of $\gamma$ on $t_{2}$ is ambiguous and depends on the sign of $s_{21}$. If goods 1 and 2 are substitutes (complements), $s_{21}$ will be positive (negative) and the optimal $t_{2}$ will increase (decrease) if $\gamma$ increases.

Let consider now the indirect effects of the change in $\gamma$ on the tax rates through $\alpha$ and $\mu$. The effect of $\gamma$ on $\mu$ should be negative. Recall that $\mu$ represents the marginal cost of raising an additional dollar of revenue, then this cost should be lower when $\gamma$ increases because a bigger fraction of the excess burden is borne by foreign consumers. The change in $\gamma$ has direct and indirect effects on $\alpha$. The direct effect (change in $\alpha$ when $\gamma$ changes, assuming everything else constant) is positive $^{10}$, which means that the marginal social utility of income increases when the fraction of good 1 purchases by foreign consumers increases. The indirect effects on $\alpha$ are less obvious and it is difficult to know the sign of them. There are indirect effects through $\mu$ and $\lambda$. The effect through $\lambda$ should be negative assuming that the marginal utility of income is a decreasing function of income and, as it was already discussed, the effect through $\mu$ should be also negative. Therefore, the total effect of $\gamma$ on $\alpha$ is ambiguous (the direct effects is positive and the indirect effects should

\footnotetext{
${ }^{10}$ Taking $\mu, \lambda$ and $t$ as constants: $\frac{\partial \alpha}{\partial \gamma}=\mu \frac{t_{1}}{(1-\gamma)^{2}} \frac{\partial x_{1}}{\partial y}>0$
} 
be negative).

Finally, the net effect of a change in $\gamma$ on $t_{1}$ is ambiguous, because the direct effect is positive and the indirect effects are ambiguous. In general, it is difficult to know the sign of the effects of a change in $\gamma$ in all tax rates. Intuitively, we can think that a change in $\gamma$ will affect the tax rate on good 1 directly, and given that the amount of revenue to be collected is constant, the tax rates on the other two goods should change too. Even if we know the sign of the effect on $t_{1}$, it is still not clear what would happen with the other tax rates. If the government, for example, increases $t_{1}$ as a result of an increase in $\gamma$, the total revenue would increase. Hence, to keep revenue constant it can then either decrease the other two tax rates or increase one and decrease the other one. ${ }^{11}$

Consider now the ratio of two tax rates:

$$
\begin{gathered}
\frac{\frac{t_{1}}{p_{1}}}{\frac{t_{2}}{p_{2}}}=\frac{-[\mu-\alpha(1-\gamma)] \varepsilon_{22}+(\mu-\alpha) \varepsilon_{12}}{[\mu-\alpha(1-\gamma)] \varepsilon_{21}-(\mu-\alpha) \varepsilon_{11}} \\
\frac{t_{1}}{\frac{t_{1}}{p_{3}}}=\frac{[\mu-\alpha(1-\gamma)] \varepsilon_{33} \varepsilon_{22}-(\mu-\alpha) \varepsilon_{12} \varepsilon_{33}}{(\mu-\alpha)\left(\varepsilon_{11} \varepsilon_{22}-\varepsilon_{21} \varepsilon_{12}\right)}
\end{gathered}
$$

Now, consider the effect of an exogenous increase in $\gamma$, the fraction of foreign consumption of good $1 .^{12}$ The total effect of this change in $\gamma$ on expressions (21) and (22) will depend on the direct effect through $\gamma$ and the indirect effects through $\mu$ and $\alpha \cdot{ }^{13}$ In the case of expression (21) the direct effect of $\gamma$ implies an increase or decrease in the ratio of the two taxes depending on

\footnotetext{
${ }^{11}$ Mathematically, although it does not offer much insight, the comparative static result with respect to $\gamma$ can be derived using the implicit function theorem.

${ }^{12} \mathrm{I}$ am assuming that the increase in $\gamma$ is due to an increase in consumption by foreign consumers, while domestic consumption remains constant.

${ }^{13}$ The change in $\gamma$ might also affect the substitution terms of the Slutzky matrix, which means that there are also effects through $\varepsilon_{11}, \varepsilon_{22}, \varepsilon_{33}, \varepsilon_{12}$, and $\varepsilon_{21}$. However, the elasticities are usually assumed to remain constant in this type of analysis (Ramsey (1927), Samuelson (1951)).
} 
weather $[\mu-\alpha(1-\gamma)]\left(\varepsilon_{22} \varepsilon_{21}-\varepsilon_{21} \varepsilon_{22}\right) \lessgtr(\mu-\alpha)\left(\varepsilon_{11} \varepsilon_{22}-\varepsilon_{21} \varepsilon_{12}\right)$, and the sign of the indirect effects through $\mu$ and $\alpha$ are ambiguous. Therefore, the sign of the total effect is indeterminate. If we look now at expression (22), we can see that the direct effect of an increase in $\gamma$ is positive ${ }^{14}$, which means that the tax rate on good 1 would increase relative to the tax rate on good 3. Again, it is difficult to know the sign of the indirect effects through $\mu$ and $\alpha$. We know that the effect on $\alpha$ is positive ${ }^{15}$ and the effect on the term $\alpha(1-\gamma)$ is negative. ${ }^{16}$ However, the sign of the total effect is again indeterminate.

Equations (21) and (22) are obviously ratios of two tax rates and tax rates are positive numbers, therefore, both ratios must be positive. However, equations (21) and (22) can be estimated having $\frac{t_{2}}{p_{2}}$ and $\frac{t_{3}}{p_{3}}$ on the left hand-side, respectively, and $\frac{t_{1}}{p_{1}}$ on the right hand-side. In this case, the coefficient on $\frac{t_{1}}{p_{1}}$ can be interpreted as the effect of a change in $\frac{t_{1}}{p_{1}}$ on $\frac{t_{2}}{p_{2}}$ or $\frac{t_{3}}{p_{3}}$. Conditional on other explanatory variables, the right hand-side of equations (21) and (22) would be captured by the coefficient on $\frac{t_{1}}{p_{1}}$ in the regressions. Let's call this coefficient $\beta$ and consider the implications of its sign.

In the case of equation (21) we would have that:

$$
-[\mu-\alpha(1-\gamma)] \varepsilon_{22}+(\mu-\alpha) \varepsilon_{12}=\beta\left[[\mu-\alpha(1-\gamma)] \varepsilon_{21}-(\mu-\alpha) \varepsilon_{11}\right]
$$

\footnotetext{
${ }^{14}$ The term $\left(\varepsilon_{11} \varepsilon_{22}-\varepsilon_{21} \varepsilon_{12}\right)$ is positive because the matrix $\tilde{S}$ is negative semidefinite.

${ }^{15}$ Taking $\mu, \lambda$ and $t$ as constants: $\frac{\partial \alpha}{\partial \gamma}=\mu \frac{t_{1}}{(1-\gamma)^{2}} \frac{\partial x_{1}}{\partial y}>0$

${ }^{16}$ Multiplying equation (15) by $(1-\gamma)$ and keeping $\lambda$, $\mu$, and $t$ constant:

$\frac{\partial \alpha(1-\gamma)}{\partial \gamma}=-\lambda-\sum t_{j} \frac{\partial x_{j}}{\partial y}<0$
} 
After some manipulation we have,

$$
(\mu-\alpha)\left(\varepsilon_{12}+\beta \varepsilon_{11}\right)-[\mu-\alpha(1-\gamma)]\left(\varepsilon_{22}+\beta \varepsilon_{21}\right)=0
$$

Now, given that $(\mu-\alpha)>0$ and $[\mu-\alpha(1-\gamma)]>0$, equation (24) can be satisfied only if $\left(\varepsilon_{12}+\beta \varepsilon_{11}\right)$ and $\left(\varepsilon_{22}+\beta \varepsilon_{21}\right)$ have the same sign. Furthermore, given that $(\mu-\alpha)<[\mu-\alpha(1-\gamma)]$ it is also needed that $\left|\varepsilon_{12}+\beta \varepsilon_{11}\right|>\left|\varepsilon_{22}+\beta \varepsilon_{21}\right|$. There can be two cases then:

\section{Case 1:}

$\varepsilon_{12}+\beta \varepsilon_{11}>0$ and $\varepsilon_{22}+\beta \varepsilon_{21}>0$. The former condition implies that if $\beta>0$ then $\varepsilon_{12}>0$ and if $\varepsilon_{12}<0$ then $\beta<0 .{ }^{17}$ The latter condition implies that $\operatorname{sign}\left\{\varepsilon_{21}\right\}=\operatorname{sign}\{\beta\}$.

\section{Case 2:}

$\varepsilon_{12}+\beta \varepsilon_{11}<0$ and $\varepsilon_{22}+\beta \varepsilon_{21}<0$. The former condition implies that if $\beta<0$ then $\varepsilon_{12}<0$.

Now, in the case of equation (22), given that the denominator of the right hand-side is positive, we have:

$$
\operatorname{sign}\left\{[\mu-\alpha(1-\gamma)] \varepsilon_{33} \varepsilon_{22}-(\mu-\alpha) \varepsilon_{12} \varepsilon_{33}\right\}=\operatorname{sign}\{\beta\}
$$

After some manipulation,

$$
\operatorname{sign}\left\{(\mu-\alpha)\left(\varepsilon_{22}-\varepsilon_{12}\right) \varepsilon_{33}+\alpha \gamma \varepsilon_{33} \varepsilon_{22}\right\}=\operatorname{sign}\{\beta\}
$$

\footnotetext{
${ }^{17}$ Recall that $(\mu-\alpha)>0, \alpha>0, \gamma>0, \varepsilon_{33}<0$, and $\varepsilon_{22}<0$.
} 
which implies that if $\beta<0$ then $\varepsilon_{12}<0$ and $\left|\varepsilon_{12}\right|>\left|\varepsilon_{22}\right|$. If $\varepsilon_{12}>0$ then $\beta>0$.

$$
\operatorname{sign}\left\{\varepsilon_{22}-\varepsilon_{12}\right\}=\operatorname{sign}\{\beta\}
$$

Given that $\varepsilon_{22}<0$, condition (27) implies that $\operatorname{sign}\left\{\varepsilon_{12}\right\}=\operatorname{sign}\{\beta\}$.

Finally, recall that $\varepsilon_{12}$ is the compensated elasticity of consumption with respect to personal income taxes and $\varepsilon_{21}$ is the compensated elasticity of labor with respect to the sales tax. If labor and consumption are complements these elasticities should both be negative, which implies that a negative $\beta$ should be expected from the regressions.

Alternatively, for analyzing the ratio of two taxes we could use the fact that $\sum_{j=0} p_{j} s_{i j}=0$, in which case expressions (21) and (22) can be rewritten as:

$$
\begin{gathered}
\frac{\frac{t_{1}}{p_{1}}}{\frac{t_{2}}{p_{2}}}=\frac{[\mu-\alpha(1-\gamma)]\left(\varepsilon_{20}+\varepsilon_{21}\right)+(\mu-\alpha) \varepsilon_{12}}{[\mu-\alpha(1-\gamma)] \varepsilon_{21}+(\mu-\alpha)\left(\varepsilon_{10}+\varepsilon_{12}\right)} \\
\frac{t_{1}}{\frac{t_{1}}{p_{3}}}=\frac{-\varepsilon_{30}\left([\mu-\alpha(1-\gamma)]\left(\varepsilon_{20}+\varepsilon_{21}\right)+(\mu-\alpha) \varepsilon_{12}\right)}{(\mu-\alpha)\left(\varepsilon_{10} \varepsilon_{20}+\varepsilon_{10} \varepsilon_{21}+\varepsilon_{12} \varepsilon_{20}\right)}
\end{gathered}
$$

As can be seen from expression (28), when $\gamma=0$ we have the standard result (Corlett and Hague (1953) and Harberger (1964)) that the government should set a higher tax on the good that is the relative complement of the numeraire $\left(\varepsilon_{i 0}\right.$ is smaller $)$. When $\gamma>0$, we have a weighted sum of compensated elasticities and it is less clear which tax rate should be higher. Now, we can have the case in which $\varepsilon_{10}$ is smaller than $\varepsilon_{20}$, for example, and still have a higher tax rate on good $2 .{ }^{18}$

In general, governments set not only statutory tax rates but also tax bases and for this reason

\footnotetext{
${ }^{18}$ When $\gamma=0, \varepsilon_{10}<\varepsilon_{20}$ implies $t_{1}>t_{2}$.
} 
effective tax rates usually differ from the statutory ones. As a way of also capturing the effect of the tax base on the optimal solution of the state government problem, it may be useful to consider the optimal solution in terms of revenues. Multiplying equations (16a) and (16b) by $x_{1} x_{2} x_{3} /(1-\gamma)$ and solving the system as before, we obtain:

$$
\left[\begin{array}{l}
\frac{t_{1} x_{1}}{1-\gamma} \\
t_{2} x_{2} \\
t_{3} x_{3}
\end{array}\right]=\left[\begin{array}{l}
R_{1} \\
R_{2} \\
R_{3}
\end{array}\right]=-\left[\begin{array}{c}
-\frac{[\mu-\alpha(1-\gamma)] s_{22} x_{1}^{2}}{\mu(1-\gamma)\left(s_{11} s_{22}-s_{21} s_{12}\right)}+\frac{(\mu-\alpha) s_{12} x_{1} x_{2}}{\mu\left(s_{11} s_{22}-s_{21} s_{12}\right)} \\
\frac{[\mu-\alpha(1-\gamma)] s_{21} x_{1} x_{2}}{\mu(1-\gamma)\left(s_{11} s_{22}-s_{21} s_{12}\right)}-\frac{(\mu-\alpha) s_{11} x_{2}^{2}}{\mu\left(s_{11} s_{22}-s_{21} s_{12}\right)} \\
\frac{(\mu-\alpha) x_{3}^{2}}{\mu s_{33}}
\end{array}\right]
$$

where $R_{i}$ is the total revenue collected from taxing good $i$. Then, the ratio of revenues that are collected from two taxes can be expressed as:

$$
\begin{gathered}
\frac{R_{1}}{R_{2}}=\left[\frac{-[\mu-\alpha(1-\gamma)] \varepsilon_{22}+(\mu-\alpha)(1-\gamma) \varepsilon_{12}}{[\mu-\alpha(1-\gamma)] \varepsilon_{21}-(\mu-\alpha)(1-\gamma) \varepsilon_{11}}\right] \frac{p_{1} x_{1}}{p_{2} x_{2}} \\
\frac{R_{1}}{R_{3}}=\left[\frac{[\mu-\alpha(1-\gamma)] \varepsilon_{33} \varepsilon_{22}-(\mu-\alpha)(1-\gamma) \varepsilon_{12} \varepsilon_{33}}{(\mu-\alpha)(1-\gamma)\left(\varepsilon_{11} \varepsilon_{22}-\varepsilon_{21} \varepsilon_{12}\right)}\right] \frac{p_{1} x_{1}}{p_{3} x_{3}}
\end{gathered}
$$

The optimal ratio is now slightly different. The expression in brackets is identical as the one obtained when considering the ratio of two tax rates (see equation (21)), but now it is multiplied by the ratio of total expenditures on the two taxed goods. The effect of this modification is quite straightforward, the optimal revenue to be collected from one good with respect to another one will be greater the bigger the relative total expenditures on that good are. Consider equation (31) for example, the optimal solution of tax rates may imply a higher tax on good 1 than on good 2, but if total expenditures on good 2 are bigger than on good 1, it is possible that the optimal revenue 
collected from good 1 be lower than the one collected from good 2 .

Again, using $\sum_{j=0} p_{j} s_{i j}=0$, expressions (31) and (32) can be rewritten as:

$$
\begin{gathered}
\frac{R_{1}}{R_{2}}=\left[\frac{[\mu-\alpha(1-\gamma)]\left(\varepsilon_{20}+\varepsilon_{21}\right)+(\mu-\alpha) \varepsilon_{12}}{[\mu-\alpha(1-\gamma)] \varepsilon_{21}+(\mu-\alpha)\left(\varepsilon_{10}+\varepsilon_{12}\right)}\right] \frac{p_{1} x_{1}}{p_{2} x_{2}} \\
\frac{R_{1}}{R_{3}}=\left[\frac{-\varepsilon_{30}\left([\mu-\alpha(1-\gamma)]\left(\varepsilon_{20}+\varepsilon_{21}\right)+(\mu-\alpha)(1-\gamma) \varepsilon_{12}\right)}{(\mu-\alpha)(1-\gamma)\left(\varepsilon_{10} \varepsilon_{20}+\varepsilon_{10} \varepsilon_{21}+\varepsilon_{12} \varepsilon_{20}\right)}\right] \frac{p_{1} x_{1}}{p_{3} x_{3}}
\end{gathered}
$$

As before, the optimal ratio of revenues is now multiplied by the ratio of total expenditures on each good. The analysis with respect to the expression in brackets is obviously the same as in the case of tax rates and the term multiplying it is not directly affected by a change in $\gamma$, so as a first order approximation it can be considered constant.

\section{Data}

I collected fiscal, economic and demographic data for the 50 U.S. states over the period 19801998. Table 1 shows the summary statistics of these data.

All the tax rates variables (sales tax rate, corporate tax rate, and personal tax rate) are statutory state tax rates. In the case of corporate income and personal income taxes I use the top statutory tax rate. However, it is not always clear what the statutory tax rate is and I had to use my judgment to define one. In the case of personal income taxes there are two circumstances in which this happens. First, some states tax personal income using a percentage of the federal income tax liability, in which case I multiply that percentage by the top statutory federal tax rate to obtain the 
Table 1: Summary Statistics

\begin{tabular}{llllll}
\hline Variable & Mean & Std. Dev. & Min. & Max. & N \\
\hline Sales Tax Rate & 0.0428 & 0.0176 & 0 & 0.08 & 950 \\
Corporate Tax Rate & 0.0673 & 0.0296 & 0 & 0.138 & 950 \\
Personal Tax Rate & 0.0594 & 0.0379 & 0 & 0.17 & 950 \\
Fraction Sales Tax Rev. & 0.3135 & 0.1430 & 0 & 0.6164 & 950 \\
Fraction Corp. Tax Rev. & 0.0694 & 0.0455 & 0 & 0.3932 & 950 \\
Fraction Pers. Tax Rev. & 0.2750 & 0.1588 & 0 & 0.6878 & 950 \\
Sales Tax Rev. per capita & 0.4474 & 0.2351 & 0 & 1.3519 & 950 \\
Corp. Tax Rev. per capita & 0.1125 & 0.1989 & 0 & 3.8388 & 950 \\
Pers. Tax Rev. per capita & 0.4081 & 0.2719 & 0 & 1.3066 & 950 \\
Income Per Capita & 224534 & 3879.25 & 13997.4 & 37338 & 950 \\
Unemployment & 6.4177 & 2.1629 & 2.4 & 18 & 950 \\
Poverty & 13.4932 & 4.1339 & 2.9 & 27.2 & 950 \\
Balanced Budget & 0.5315 & 0.4992 & 0 & 1 & 950 \\
Expenditure Limit & 0.3589 & 0.4799 & 0 & 1 & 950 \\
Revenue Limit & 0.1094 & 0.2134 & 0 & 1 & 950 \\
Grants Per Capita & 0.7095 & 0.2767 & 0.3196 & 4.005 & 950 \\
Fraction GSP Hotel & 0.0132 & 0.0236 & 0.00274 & 0.2042 & 950 \\
Elder 65 & 12.1327 & 2.1861 & 3 & 18.6 & 950 \\
Population & 4945.42 & 5327.9 & 402 & 32667 & 950 \\
\hline
\end{tabular}

state tax rate. ${ }^{19}$ Second, some states tax only interest and dividends, in which case I considered the tax rate to be zero. In the case of corporate income taxes, there are two states that impose a tax that is somewhat different: Michigan and Texas. Michigan, since 1976, uses a single business tax, imposing a flat rate on the sum of federal taxable income of the business, compensation to employees, dividends, interest and royalties paid. Texas, since 1991, uses a franchised tax on earned surplus, defined as the federal income tax apportioned to the state. In both cases I consider the tax rate on these taxes as a top statutory tax rate on corporate income tax.

The fraction of tax revenue variables are the fraction of total state tax revenue that is collected from each of these three taxes. The tax revenue per capita variables are the total revenue collected

\footnotetext{
${ }^{19}$ For example, Vermont in 1997 taxed personal income with a $25 \%$ of the federal income tax liability and the top statutory federal tax rate was $39.6 \%$. I set the tax rate equal to $9.9 \%$ then.
} 
(in millions) from each tax divided by the total population of the state.

The variable Income per capita is the state personal income per capita in dollars, as calculated by the Bureau of Economic Analysis, deflated by the U.S. GDP price deflator. The variable unemployment is the state unemployment rate as percentage of the civilian labor force, estimated by the Bureau of Labor Statistics. The variables poverty, population and elder 65 are the percentage of persons in the state below the poverty level, the state population in thousands, and the percentage of the population above 65 years old respectively, all of them as estimated by the U.S. Census Bureau.

State governments face several statutory constraints when designing their budgets. Several states face expenditures and/or revenue limitations, which constrain the annual growth of them either to a fixed rate or to one based on one or more of the following variables: inflation rate, population growth, growth of personal income, and ratio of revenue to personal income. Many states also have statutory or constitutional requirements to balance their budgets. The two most common requirements are that the governor must submit a balanced budget and that the legislature must pass a balanced budget. Using information from the Advisory Commission on Intergovernmental Relations and the Book of the States, I constructed a set of dummy variables for capturing the effects of these budget limits. The variables Expenditure Limit and Revenue Limit are a dummy equal to one if the state has a constitutional or statutory provision that constraints the annual growth of expenditures or revenues respectively, and zero otherwise. The variable Balanced Budget is equal to one if the state legislature must pass a balanced budget, and zero otherwise.

The variable Grants Per Capita is the amount, in dollars, of federal grants received by each state divided by the state's population as reported by The Council of State Governments, deflated 
by the U.S. GDP price deflator.

One of the difficulties of estimating the effects of one tax on another one within the same state is that state governments set all taxes simultaneously. Therefore, the sales tax rate, for example, is correlated with the error term in the tax setting equation of the other taxes. A potential solution for this problem is the use of instrumental variables. In this particular case, for identifying the effects of each tax on one another it would be necessary to have at least on instrument for each tax, which is a hard task. In the theoretical analysis I used $\gamma$, the fraction of total consumption by foreign citizens in each state, as a variable that would affect the sales tax rate directly but not the other taxes. A reliable measure of $\gamma$ can be a suitable instrument if it is highly correlated with the sales tax (rate or fraction of revenue) and not correlated with unobserved variables that determine personal and corporate income taxes. As a proxy for $\gamma$ I use the variable Fraction GSP Hotel, which is the fraction of the state gross product that corresponds to the hotels and lodging industry (SIC code 70), according with the Bureau of Economic Analysis. ${ }^{20}$ The use of the fraction of GSP that comes from lodging as an instrumental variable for the sales tax allows identifying the effects of the sales tax on personal and corporate income taxes. ${ }^{21}$

\footnotetext{
${ }^{20}$ There exist some alternatives proxies for the state sales to foreign citizens that I could not use. The Travel Industry Association of America, for example, calculates the impact of international visitor spending on state economies, but it is available for only few years. The Census Bureau reports the number of visitors each state receives, but is available only for some states and also for few years.

${ }^{21}$ One potential concern with the use of this instrument is that the fraction of GSP from hotels and lodging can be capturing several things non related at all with the actual number of visitors or the expenditures of foreign citizens in each state. As a way to explore this possibility I ran a regression using the fraction of GSP from lodging as a dependent variable and the other measures described in the previous footnote (international travel expenditures, number of international visitors) for which I have few observations. The results show that the fraction of GSP from hotels is not only strongly and positively correlated with these alternative measures, but it also explains around $45 \%$ of the variation. The results of these regressions are shown in the Appendix.
} 


\section{Results}

\subsection{Tax Rates}

Table 2 shows the results of estimating the relationship between the corporate income and sales tax rates. The first column shows the results when OLS state fixed-effects are used for the estimation. The coefficient of the sales tax rate is positive and significant. The elasticity of the corporate tax rate with respect to the sales tax rate is, at mean values, 0.2 . The second column shows the results of estimating the same equation when instrumental variables are used. As can be seen from the table, when the endogeneity of the sales tax rate is taken into account in the estimation the coefficient changes dramatically. Even though the coefficients of most of the variables are very similar as before, now the coefficient of the sales tax rate is negative and significant. Evaluated at mean values, now the elasticity of the corporate tax rate with respect to the sales tax rate is -0.306 . Hence, a one percent increase in the sales tax rate of a state is associated with a roughly one-third percent decrease in the corporate income tax rate of the same state, ceteris paribus.

The variable income per capita is negative and significant, showing that states where the population is richer have lower corporate income taxes. Evaluated at mean values, a one percent increase in income per capita is associated with a 0.52 percent decrease in the corporate tax rate. The coefficient of unemployment is positive and non-significant. My prior was a negative sign for this variable because states with high unemployment rates may want attract investment to generate more jobs. It is possible that this effect might be captured by the poverty rate, which is negative and significant. A one percent increase in the poverty rate of a state is associated, at mean values, with a 0.085 percent decrease in the corporate tax rate of the state. 


\begin{tabular}{lcc} 
Table 2: Sales Taxes and Corporate & Income Taxes \\
\hline Corporate Tax Rate & OLS & IV \\
\hline Sales Tax Rate & 0.314 & -0.478 \\
& $(0.053)$ & $(0.212)$ \\
Income per capita & $-6.90 \mathrm{e}-07$ & $-1.56 \mathrm{e}-06$ \\
& $(2.54 \mathrm{e}-07)$ & $(3.66 \mathrm{e}-07)$ \\
Unemployment & 0.0002 & 0.00018 \\
& $(0.0002)$ & $(0.0002)$ \\
Poverty & -0.0003 & -0.00042 \\
& $(0.0001)$ & $(0.0001)$ \\
Balanced Budget & -0.0008 & 0.0002 \\
& $(0.0007)$ & $(0.0008)$ \\
Expenditure Limit & 0.0032 & 0.0029 \\
& $(0.0010)$ & $(0.0011)$ \\
Revenue Limit & 0.0017 & 0.0021 \\
& $(0.0010)$ & $(0.0011)$ \\
Population & $-1.54 \mathrm{e}-06$ & $-4.88 \mathrm{e}-07$ \\
& $(4.5 \mathrm{e}-07)$ & $(6.97 \mathrm{e}-07)$ \\
Constant & 0.0720 & 0.1095 \\
Fixed Effects & $(0.0059)$ & $(0.0141)$ \\
Year Dummies & yes & yes \\
\hline N & yes & yes \\
Wald Chi ${ }^{2}$ & 950 & 950 \\
F & & 81388.7 \\
R & 7.89 & \\
\hline
\end{tabular}

Among the budget limit set of dummies, only the limits on the growth of expenditures and revenues were significant. I expected a negative sign for these two variables because a state government facing a binding limit on its expenditures and /or revenues would need to raise less revenue than otherwise, which would imply lower tax rates. Surprisingly, both have a positive coefficient showing that these limits are associated with higher corporate income taxes. There are two potential explanations for this. First, these limits on expenditures and/or revenues are annual limits that state governments face every year independently of what happened the previous year. Therefore, 
if the limit was not binding for one year the extra room for increasing revenues or expenditures during that year cannot be carry forward to the next year. State governments then have incentives to hit the limits every year and the data is showing that the states with limits do increase taxes to reach the limit every year. A second possible explanation is that the regression is mainly capturing the cross-sectional variation of these limits because they do not vary much over time. It is quite reasonable to think that these limits on the growth of expenditures and revenues were imposed primarily in states with higher taxes and, therefore, the regression is showing this positive cross-sectional correlation between taxes and statutory limits. ${ }^{22}$ The variable balanced budget, even though not significant, has a positive coefficient as I expected. If the legislature of a state must pass a balance budget it has to either increase taxes or reduce expenditures, which implies a non-negative correlation with tax rates.

The coefficient of population is negative and non significant. Population usually captures the level of business activity and therefore it might be considered a proxy for the base of the tax in this case. A negative sign then, shows that an increase in the tax base is associated with a decrease in the tax rate (the causality could go either way of course).

Table 3 shows the results of estimating the relationship between the personal income tax rate and the sales tax rate. When OLS fixed effects are used for the estimation, the coefficient on the sales tax rate is positive but statistically non significant. The elasticity of the personal tax rate with respect to the sales tax rate, calculated at mean values, is 0.06 . If instrumental variables

\footnotetext{
${ }^{22}$ This explanation opens the possibility that these limits be endogenous and, therefore, the estimated coefficients in the regression are biased. Several of these limits are constitutional limits and were imposed more than 50 years ago, so they are probably not correlated with the tax rates of the last 15 years. Nevertheless, I estimated the same regression without using the budget limit dummies as a comparison and the results were very similar.
} 
are used instead, the coefficient becomes negative and significant. Evaluated at the means, the elasticity of the personal tax rate with respect to the sales tax rate is -0.466 . Consequently, a one percent increase in the sales tax rate of a state is associated with a roughly half percent decrease in the personal income tax rate, ceteris paribus.

\begin{tabular}{|c|c|c|}
\hline Personal Tax Rate & OLS & IV \\
\hline \multirow[t]{2}{*}{ Sales Tax Rate } & 0.0688 & -0.6474 \\
\hline & $(0.1091)$ & $(0.3303)$ \\
\hline \multirow[t]{2}{*}{ Income per capita } & $-1.11 \mathrm{e}-06$ & $-2.05 \mathrm{e}-06$ \\
\hline & $(5.23 \mathrm{e}-07)$ & $(1.16 \mathrm{e}-06)$ \\
\hline \multirow[t]{2}{*}{ Unemployment } & 0.0009 & 0.00086 \\
\hline & $(0.0004)$ & $(0.0004)$ \\
\hline \multirow{2}{*}{ Poverty } & 0.00006 & -0.00009 \\
\hline & $(0.0002)$ & $(0.0002)$ \\
\hline \multirow[t]{2}{*}{ Balanced Budget } & -0.0025 & -0.0019 \\
\hline & $(0.0014)$ & $(0.0015)$ \\
\hline \multirow[t]{2}{*}{ Expenditure Limit } & 0.0050 & 0.0049 \\
\hline & $(0.0020)$ & $(0.0021)$ \\
\hline \multirow[t]{2}{*}{ Revenue Limit } & 0.00037 & 0.0024 \\
\hline & $(0.0026)$ & $(0.0015)$ \\
\hline \multirow[t]{2}{*}{ Elder 65} & 0.0037 & 0.0025 \\
\hline & $(0.0013)$ & $(0.0019)$ \\
\hline \multirow[t]{2}{*}{ Population } & $1.33 \mathrm{e}-06$ & $2.04 \mathrm{e}-06$ \\
\hline & $(9.53 \mathrm{e}-07)$ & $(1.24 \mathrm{e}-06)$ \\
\hline \multirow[t]{2}{*}{ Constant } & 0.0288 & 0.8282 \\
\hline & $(0.0219)$ & $(0.0623)$ \\
\hline Fixed Effects & yes & yes \\
\hline Year Dummies & yes & yes \\
\hline $\mathrm{N}$ & 950 & 950 \\
\hline Wald $\mathrm{Chi}^{2}$ & & 18442.4 \\
\hline $\mathrm{F}$ & 5.04 & \\
\hline $\mathrm{R}^{2}$ & 0.1214 & 0.1054 \\
\hline
\end{tabular}

The coefficient of income per capita is negative and significant at $10 \%$ only, showing that more affluent states have lower top statutory tax rates on personal income. The elasticity of the corporate tax rate with respect to income per capita is -0.078 at mean values. 
The effects of unemployment and poverty are significant and with opposite signs. Higher unemployment rates are associated with higher personal tax rates and higher poverty rates with lower ones. The magnitude of the effects is small, a one percent increase in the unemployment rate and a one percent increase in the poverty rate are related to a 0.09 percent increase and a 0.0004 percent decrease in the personal tax rate respectively.

Expenditure Limit is the only budget limit variable that is significant at $5 \%$. Its coefficient is positive, as in the case of corporate income taxes, showing that states with statutory requirements that limit their annual growth of expenditures tend to have higher personal tax rates. The variable Revenue Limit is positive but significant only at $10 \%$ and Balanced Budget is negative but non significant.

The variable Elder 65 has the expected sign, states with higher fractions of elder people in the population have higher personal taxes, but it is not significant. The coefficient on population is positive, non significant at $5 \%$ but statistically significant at $10 \%$. A one percent increase in the state population is related to a 0.03 percent increase in the personal tax rate. The effect is then the opposite as the one on corporate taxes, a higher level of business activity is related to higher personal tax rates.

Table 4 shows the first-stage regression of the instrumental variables regressions (the first-stage regression is identical for the two instrumental variables regressions shown in the second column of tables 2 and 3$)$.

The variable Fraction GSP Hotel is positive as expected and significant, showing that a higher fraction of the state product corresponding to hotels and lodging is associated with higher sales tax rates. A one percent increase in the fraction of the GSP corresponding to hotel and lodging is 
related to a 0.034 percent increase in the sales tax rate of the state. If this variable is a good proxy for the fraction of consumption of foreign citizens in the state, this result is consistent with some empirical findings of the tax competition literature. If a neighbor of state $i$, say state $j$, increases its sales tax rate, the citizens of state $j$ will engage in cross-border shopping with state $i$ and this will increase the fraction of consumption by foreign citizens in state $i$. As a result, state $i$ can now increase its sales tax rate to collect some extra revenue, reduce some other taxes, and somehow "export" some of the burden of its taxes.

The coefficient of the fraction of elder people is negative and significant, confirming the intuition that states with a higher fraction of elder people in the population have lower sales tax rates. The magnitude of the impact is quite important, a one percent increase in the fraction of the population older than 65 years old is associated, at mean values, with a 0.57 percent decrease in the sales tax rate.

The variable Grants Per Capita was never significant in any of the regressions and the results did not change when it was excluded, so I dropped it from the final specification. I also consider the following variables that might affect the tax setting decision of a state government: percentage of the state population voting democrat in the closest presidential election, the ratio of state debt to state product, state debt per capita, the fraction of the population that are high school graduates and, a dummy variable equal to one if the state has a statutory or constitutional provision requiring a supermajority voting to increase taxes. However, they were never significant and the results were basically identical if they were included or not.

Finally, it is important to mention that one concern with the use of tax rates as dependent variables is that they are bounded within zero and one. However, even if the sample contains 


\begin{tabular}{ll}
\multicolumn{2}{c}{ Table 4: First-Stage Regression } \\
\hline Sales Tax Rate & OLS \\
\hline Income Per Capita & $-1.13 \mathrm{e}-06$ \\
& $(1.52 \mathrm{e}-07)$ \\
Unemployment & -0.00012 \\
& $(0.0001)$ \\
Poverty & -0.00008 \\
& $(0.00008)$ \\
Balanced Budget & 0.00091 \\
& $(0.0004)$ \\
Expenditure Limit & 0.00042 \\
& $(0.0006)$ \\
Revenue Limit & 0.0008 \\
& $(0.0008)$ \\
Fraction GSP Hotel & 0.1362 \\
& $(0.0663)$ \\
Elder 65 & -0.002 \\
& $(0.0004)$ \\
Population & $9.43 \mathrm{e}-07$ \\
& $(12.91 \mathrm{e}-07)$ \\
Constant & 0.0824 \\
Fixed Effects & $(0.0066)$ \\
Year Dummies & yes \\
N & yes \\
F & 950 \\
R & 30.99 \\
& 0.4894 \\
\hline &
\end{tabular}

several zero tax rates $^{23}$, the regressions do not predict negative tax rates at all for the case of corporate income and sales tax and just two for the case of personal income tax. For this reason, and following everybody else in the tax literature I decided not to use a Tobit model to estimate the regressions.

\footnotetext{
${ }^{23}$ Over the whole period $1980-1998$, there are five states ( $10 \%$ of the sample) with no sales tax, four ( $8 \%$ of the sample) with no corporate income tax, and nine (18\% of the sample) with no personal income tax.
} 


\subsection{Tax Revenues}

Table 5 presents the results of estimating the relationship between the tax revenue per capita from corporate taxes and the tax revenue per capita from sales taxes. ${ }^{24}$ When OLS are used for the estimation, the coefficient of the sales tax revenue per capita is negative but not significant. If instrumental variables are used to correct for the endogeneity of the sales tax revenue per capita, the coefficient is again negative, but statistically significant and almost twenty times bigger in absolute value. The elasticity, at mean values, between the corporate tax revenue per capita and the sales tax revenue per capita is -3.01 . Hence, a one percent increase in the sales tax revenue per capita is associated with a $3 \%$ decrease in the corporate tax revenue per capita. The mean values of corporate income and sales tax revenues per capita in the sample are $\$ 113$ and $\$ 448$ respectively. Therefore, a $\$ 4.5$ increase in the sales tax revenue per capita is associated with a $\$ 3.4$ reduction in the corporate income tax revenue per capita, everything else constant.

The coefficient for income per capita is positive and significant. The elasticity with respect to income per capita, at mean values, is 11.98 . Hence, a one percent increase in the income per capita is associated with almost a $12 \%$ increase in the revenue per capita collected from corporate income taxes. The mean income per capita in the sample is $\$ 22,454$ and the mean revenue per capita from corporate taxes is $\$ 113$. Therefore, an increase of $\$ 225$ in the income per capita of a state is associated, on average, with a $\$ 3.4$ increase in the corporate taxes revenue per capita. The variables unemployment and poverty are both negative and statistically insignificant.

\footnotetext{
${ }^{24} \mathrm{I}$ also estimated the same regressions using the fractions of total state tax revenues collected from each tax. However, one of the concerns with the use of fractions of revenues is that there is an implicit constraint to be considered, which is that the fractions should add to one (given than I am omitting excise taxes from the analysis, the fractions add to less than one, but still the concern is a valid one). The results of the estimation are shown in the appendix.
} 
Table 5: Corporate Tax Revenue Per Capita

\begin{tabular}{lcc}
\hline Corporate Tax Revenue per capita & OLS & IV \\
\hline Sales Tax Revenue per capita & -0.0348 & -0.7568 \\
Income per capita & $(0.0836)$ & $(0.3601)$ \\
& 0.00005 & 0.00006 \\
Unemployment & $(5.21 \mathrm{e}-06)$ & $(8.67 \mathrm{e}-06)$ \\
& -0.0034 & -0.0045 \\
Poverty & $(0.0044)$ & $(0.0046)$ \\
& -0.0027 & -0.0038 \\
Balanced Budget & $(0.0027)$ & $(0.0029)$ \\
& -0.007 & -0.0026 \\
Expenditure Limit & $(0.0146)$ & $(0.0154)$ \\
& -0.0757 & -0.0602 \\
Revenue Limit & $(0.0213)$ & $(0.0234)$ \\
& -0.0202 & -0.0312 \\
Elder 65 & $(0.0276)$ & $(0.0292)$ \\
& 0.0307 & 0.0247 \\
Population & $(0.0132)$ & $(0.015)$ \\
& 0.00001 & 0.00003 \\
Constant & $(9.75 \mathrm{e}-06)$ & $(0.00001)$ \\
& -1.0787 & -1.0668 \\
Fixed Effects & $(0.2149)$ & $(0.2239)$ \\
Year Dummies & yes & yes \\
\hline N & yes & yes \\
Wald Chi ${ }^{2}$ & 950 & 950 \\
F & & 752.31 \\
& & \\
\end{tabular}

Although all the budget limit dummies are negative, only the variable expenditure limit is significant, showing that states facing a constraint in the rate of growth of their expenditures collect lower revenue per capita from corporate taxes.

The coefficient for population is positive and significant, even though the magnitude of the effect is somewhat small. A one percent increase in the population of a state is associated, at mean values, with a $1.32 \%$ decrease in the revenue per capita that is collected using corporate taxes. 
Table 6 presents the results of estimating the relationship between the revenues per capita collected from personal income taxes and sales taxes. The first column show the results when OLS fixed effects are used for the estimation. As can be seen from the table, the coefficient of the sales tax revenue per capita is negative but insignificant. The second column shows the results when instrumental variables are used in the estimation to control for the endogeneity of the sales tax revenue per capita. The coefficient on the sales tax revenue per capita is again negative, but now is significant and almost twenty time bigger in magnitude. The elasticity, calculated at mean values, is -0.89 . Hence, a one percent increase in the revenue per capita collected from sales taxes is associated with a $0.9 \%$ percent decrease in the revenue per capita collected from personal taxes. The mean values of the sales and personal income tax revenues per capita are $\$ 448$ and $\$ 408$ respectively. Therefore, a $\$ 4.5$ increase in the sales tax revenue per capita is related to a $\$ 3.63$ decrease in the personal income tax revenue per capita, ceteris paribus.

The variable income per capita is positive and significant, showing that wealthier states collect larger revenues per capita from personal income taxes. A one percent increase in the income per capita of a state is related, at mean values, to a 2.8 percent increase in the state tax revenue per capita that comes from personal taxes.

The coefficient for unemployment is positive but non statistically significant. The coefficient for poverty is also positive, but significant. The positive relationship between poverty rate and the amount of revenue per capita collected from personal taxes might be due to redistributive purposes, even though the effect is somewhat small. A one percent increase in the poverty rate is associated with a 0.11 percent increase in the revenue per capita collected through personal income taxes.

The balanced budget dummy is positive and non significant. The expenditure and revenue limit 
Table 6: Personal Tax Revenue Per Capita

\begin{tabular}{lcc}
\hline Personal Tax Revenue per capita & OLS & IV \\
\hline Sales Tax Revenue per capita & -0.0473 & -0.8184 \\
Income per capita & $(0.0403)$ & $(0.1985)$ \\
& 0.00003 & 0.00005 \\
Unemployment & $(2.51 \mathrm{e}-06)$ & $(4.78 \mathrm{e}-06)$ \\
& 0.0037 & 0.0025 \\
Poverty & $(0.0021)$ & $(0.0025)$ \\
& 0.0046 & 0.0034 \\
Balanced Budget & $(0.0064)$ & $(0.0016)$ \\
& -0.0004 & 0.0043 \\
Expenditure Limit & $(0.0070)$ & $(0.0085)$ \\
& 0.0267 & 0.0432 \\
Revenue Limit & $(0.0103)$ & $(0.0129)$ \\
& 0.0412 & 0.02939 \\
Elder 65 & $(0.0133)$ & $(0.01613)$ \\
& 0.0048 & 0.00165 \\
Population & $(0.0064)$ & $(0.0077)$ \\
& -0.00002 & $-5.39 \mathrm{e}-06$ \\
Constant & $(4.7 \mathrm{e}-06)$ & $(6.77 \mathrm{e}-06)$ \\
& -0.3563 & -0.3436 \\
Fixed Effects & $(0.1036)$ & $(0.1234)$ \\
Year Dummies & yes & yes \\
\hline N & yes & yes \\
Wald Chi ${ }^{2}$ & 950 & 950 \\
F & & 28127.04 \\
& & \\
\end{tabular}

dummies are both positive and significant at 5\% and 10\% respectively. States that face constraints on the growth of their expenditures and/or revenues in their budgets collect larger tax revenue per capita from personal taxes than states that do not face those constraints.

The variable Elder 65 is negative but, contrary to what I expected, not significant. The coefficient for population is negative but also statistically not different from zero.

Table 7 shows the first-stage regression of the instrumental variables regressions (the first-stage 
regression is again identical for the two IV regressions previously shown).

Table 7: Firs-Stage Regression

\begin{tabular}{ll}
\hline Sales Tax Revenue per capita & OLS \\
\hline Income Per Capita & 0.00002 \\
& $(1.94 \mathrm{e}-06)$ \\
Unemployment & -0.0021 \\
& $(0.0017)$ \\
Poverty & -0.0018 \\
& $(0.0010)$ \\
Balanced Budget & 0.0087 \\
& $(0.0057)$ \\
Expenditure Limit & 0.0246 \\
& $(0.0083)$ \\
Revenue Limit & -0.0125 \\
& $(0.0108)$ \\
Fraction GSP Hotel & 6.243 \\
& $(0.8477)$ \\
Elder 65 & -0.0184 \\
& $(0.0053)$ \\
Population & 0.00002 \\
& $(3.78 \mathrm{e}-06)$ \\
Constant & 0.0799 \\
Fixed Effects & $(0.0848)$ \\
Year Dummies & yes \\
\hline N & yes \\
F & 950 \\
\hline
\end{tabular}

The variable Fraction GSP Hotel is again positive, as expected, and significant, showing that a higher fraction of the GSP corresponding to hotels and lodging is correlated with higher sales tax revenues per capita. A one percent increase in the fraction of the GSP from hotels and lodging is associated with a 0.15 percent increase in the revenue per capita collected from sales tax.

The coefficient for the variable Elder 65 is negative and significant, showing that the revenue per capita collected from sales taxes is lower in states with a higher proportion of elder people in 
the population. A one percent increase in the fraction of the population older than 65 years old is associated, at mean values, with a 0.5 percent decrease in the revenue per capita that comes from sales taxes.

\section{Conclusions}

The empirical evidence in the literature has shown that the fiscal policy of a U.S. state is influenced by the fiscal policies of its neighbors. In the same way, it is natural to think that decisions regarding one instrument of fiscal policy influence the decisions regarding other available instruments within each state. Specifically, I think that state governments do not set taxes considering one tax at a time or each different tax based only on its own effects, but rather consider a full tax package, setting all taxes simultaneously. An important question then, is how one specific tax affects the other taxes within the same state. This paper attempts to address this question empirically. Using instrumental variables I estimate the effect of sales taxes on personal and corporate income taxes within a state. The results show that one percent increase in the sales tax rate is associated with a 0.47 and a 0.3 percent decrease in the personal and corporate income tax rates respectively. In terms of revenues, the results show that a one percent decrease in the revenue per capita collected from sales taxes is associated with a 3 and 0.9 percent increase in the revenue per capita collected from corporate and personal income taxes respectively. At mean values, the revenue results imply that an increase of $\$ 4.5$ in the sales tax revenue per capita is associated with a decreased of $\$ 3.4$ in the corporate income tax revenue per capita or a $\$ 3.63$ decreased in the personal income revenue per capita. 
The importance of these results is that they show not only that taxes are in fact interdependent within one jurisdiction, but also that state governments try to keep their expenditures constant and for that purpose they compensate the decline in revenues from one tax increasing the revenues from other taxes. A natural extension of this paper is to estimate the effects of all the three taxes among themselves, finding for this purpose suitable instruments for the corporate and personal income taxes. Even more interesting, though much more difficult, would be to also include excise taxes, which represent a non negligible fraction of state tax revenues. 


\section{Appendix A}

Figure 3 shows the average fraction of total state tax revenue collected from each of the same three taxes over the period 1980-1998. It seems that on average, states have been relying more on personal income taxes and less on corporate income taxes, while leaving the role of sales taxes relatively constant.

Figure 3:

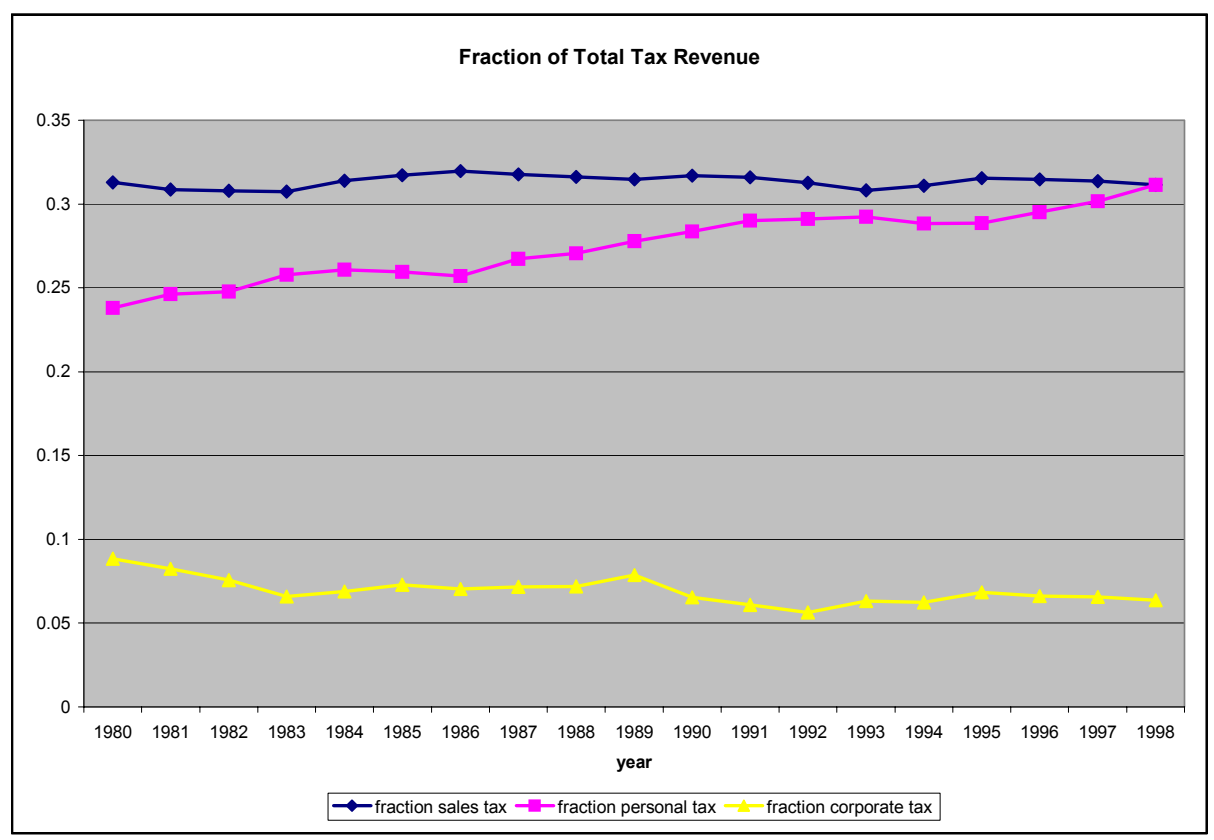




\section{Appendix B}

Table 8: Fraction of GSP from Hotels and Accomodations

\begin{tabular}{llllll}
\hline & $(1)$ & $(2)$ & $(3)$ & $(4)$ & $(5)$ \\
\hline Visitors p.c. & 0.00607 & & 0.0074 & & 0.0066 \\
& $(0.0025)$ & & $(0.0018)$ & & $(0.0032)$ \\
Expenditures. p.c. & & 0.00056 & & 0.0037 & 0.0013 \\
& & $(0.00014)$ & & $(0.0010)$ & $(0.0016)$ \\
\hline $\mathrm{R}^{2}$ & 0.4524 & 0.1080 & 0.4580 & 0.2283 & 0.3946 \\
$\mathrm{~F}$ & 1.49 & 7.63 & 15.43 & 4.46 & 4.49 \\
$\mathrm{n}$ & 174 & 250 & 129 & 129 & 129 \\
\hline
\end{tabular}

The variable Expenditures p.c. is the amount (in millions) of international visitor expenditures per capita and contains data for 50 states for the years 1980, 1990, 1994, 1996 and 1997.

The variable Visitors per capita contains data for 46 states for the years 1980, 1996, and 1998 (not all years for each state).

The models (3) and (4) are identical to models (1) and (2) respectively, but they are estimated using the same observations of model (5) to make the regressions comparable. 


\section{Appendix C}

Table 9 presents the results of estimating the relationship between the fraction of tax revenue from corporate taxes and the fraction of tax revenue from sales taxes.

The OLS elasticity of the fraction of corporate tax revenue with respect to the fraction of sales tax revenue is -0.51 . The IV elasticity at mean values is -0.16 , even though is not statistically different from zero.

Table 9: Fraction Corporate Tax Revenue

\begin{tabular}{lcc}
\hline Fraction Corporate Tax Revenue & OLS & IV \\
\hline Fraction Sales Tax Revenue & -0.1141 & -0.0359 \\
Income per capita & $(0.0219)$ & $(0.0281)$ \\
& $-1.05 \mathrm{e}-06$ & $-1.13 \mathrm{e}-06$ \\
Unemployment & $(7.31 \mathrm{e}-07)$ & $(7.35 \mathrm{e}-07)$ \\
& -0.0031 & -0.0031 \\
Poverty & $(0.0006)$ & $(0.0006)$ \\
& -0.0011 & -0.0010 \\
Balanced Budget & $(0.0003)$ & $(0.0003)$ \\
& -0.0003 & -0.0006 \\
Expenditure Limit & $(0.002)$ & $(0.002)$ \\
& -0.0101 & -0.0101 \\
Revenue Limit & $(0.003)$ & $(0.003)$ \\
& -0.0043 & -0.0041 \\
Grants Per Capita & $(0.0039)$ & $(0.0039)$ \\
& 0.0075 & -0.0187 \\
Population & $(0.0053)$ & $(0.0082)$ \\
& $1.23 \mathrm{e}-06$ & $2.71 \mathrm{e}-07$ \\
Constant & $(1.34 \mathrm{e}-06)$ & $(1.82 \mathrm{e}-06)$ \\
& 0.1702 & 0.1553 \\
Fixed Effects & $(0.0174)$ & $(0.0376)$ \\
Year Dummies & yes & yes \\
N & yes & yes \\
Wald Chi ${ }^{2}$ & 950 & 950 \\
F & & 12496.9 \\
\hline
\end{tabular}


Table 10 presents the results of estimating the relationship between the fractions of total tax revenue collected from personal income taxes and sales taxes.

The OLS elasticity of the fraction of personal tax revenue with respect to the fraction of sales tax revenue is -0.45 . The IV elasticity, calculated at mean values, is -0.83 . Hence, a one percent increase in the fraction of tax revenue collected from sales taxes is associated with a 0.8 percent decrease in the fraction of tax revenue collected from personal taxes.

It is possible that this result explains why the effect of the fraction of revenue from sales tax on the fraction of revenue from corporate taxes is non significant. A large portion of the change in the fraction of revenue collected using sales taxes is compensated using personal taxes and, therefore, the effect on the fraction of revenue collected through corporate taxes is close to zero. ${ }^{25}$

Table 11 shows the first-stage regression of the instrumental variables regressions (the first-stage regression is again identical for the two IV regressions previously shown).

The variable Fraction GSP Hotel is positive and significant. A one percent increase in the fraction of the GSP from hotels and lodging is associated, on average, with a 0.05 percent increase in the fraction of tax revenue collected from sales tax.

\footnotetext{
${ }^{25}$ It is true that if the state government wants to keep the total tax revenue constant it has to fully compensate the increase or decrease in the fraction of taxes collected from sales taxes, but that can be done using, for example, excise taxes (which are not considered here).
} 
Table 10: Fraction Personal Tax Revenue

\begin{tabular}{lcc}
\hline Fraction Personal Tax Revenue & OLS & IV \\
\hline Fraction Sales Tax Revenue & -0.3979 & -0.7294 \\
& $(0.0308)$ & $(0.2382)$ \\
Income per capita & $3.14 \mathrm{e}-06$ & $2.91 \mathrm{e}-06$ \\
& $(1.05 \mathrm{e}-06)$ & $(1.13 \mathrm{e}-06)$ \\
Unemployment & 0.0013 & 0.0015 \\
& $(0.0008)$ & $(0.009)$ \\
Poverty & 0.0018 & 0.0018 \\
& $(0.0005)$ & $(0.0005)$ \\
Balanced Budget & -0.0028 & -0.0021 \\
& $(0.0029)$ & $(0.0031)$ \\
Expenditure Limit & 0.0128 & 0.0149 \\
& $(0.0043)$ & $(0.0048)$ \\
Revenue Limit & 0.0131 & 0.0127 \\
& $(0.0055)$ & $(0.0059)$ \\
Grants Per Capita & -0.0068 & -0.0145 \\
& $(0.0075)$ & $(0.0097)$ \\
Elder 65 & -0.0033 & -0.0055 \\
& $(0.0026)$ & $(0.0032)$ \\
Population & $-6.58 \mathrm{e}-06$ & $-4 \mathrm{e}-06$ \\
& $(1.95 \mathrm{e}-06)$ & $(2.77 \mathrm{e}-06)$ \\
Constant & 0.3430 & 0.4663 \\
& $(0.0434)$ & $(0.0992)$ \\
Fixed Effects & yes & yes \\
Year Dummies & yes & yes \\
\hline N & 950 & 950 \\
F & & 88353.85 \\
& & \\
\end{tabular}


Table 11: Firs-Stage Regression

\begin{tabular}{ll}
\hline Fraction Sales Tax Revenue & OLS \\
\hline Income Per Capita & $-1.22 \mathrm{e}-06$ \\
& $(1.15 \mathrm{e}-06)$ \\
Unemployment & 0.00034 \\
& $(0.0009)$ \\
Poverty & -0.0002 \\
& $(0.0006)$ \\
Balanced Budget & 0.0035 \\
& $(0.0032)$ \\
Expenditure Limit & -0.010 \\
& $(0.0045)$ \\
Revenue Limit & -0.0005 \\
& $(0.0006)$ \\
Grants Per Capita & -0.0187 \\
& $(0.0082)$ \\
Fraction GSP Hotel & 1.5217 \\
& $(0.3703)$ \\
Elder 65 & -0.0090 \\
& $(0.0029)$ \\
Population & $7.26 \mathrm{e}-06$ \\
& $(2.11 \mathrm{e}-06)$ \\
Constant & 0.4370 \\
Fixed Effects & $(0.0482)$ \\
Year Dummies & yes \\
N & yes \\
R & 950 \\
& 12.55 \\
& 0.1757 \\
\hline
\end{tabular}




\section{References}

Advisory Commission on Intergovernmental Relations, "Significant Features of Fiscal Federalism", Volumes 1 and 2, several years.

Atkinson, Anthony and Joseph Stiglitz (1972), "The Structure of Indirect Taxation and Economic Efficiency", Journal of Public Economics 1, pages 97-119.

Atkinson, Anthony and Joseph Stiglitz (1980), "Lectures in Public Economics", McGraw-Hill, New York.

Auerbach, Alan J. (1985), "The Theory of Excess Burden and Optimal Taxation", in: Alan Auerbach and Martin Feldstein (eds.)Handbook of Public Economics, Vol. 1, Chapter 2, pages 61-127.

Auerbach, Alan J. and James R. Hines Jr. (2001), "Taxation and Economic Efficiency", NBER Working Paper No. 8181.

Brett, Craig and Joris Pinske (2000), "The Determinants of Municipal Tax Rates in British Columbia", Canadian Journal of Economics 33(3), pages 695-714.

Buettner, Thiess (2001), "Local Business Taxation and Competition for Capital: The Choice of the Tax Rate", Regional Science and Urban Economics 31, pages 215-245.

Büttner, Thiess (1999), "Determinants of Tax Rates in Local Capital Income Taxation: A Theoretical Model and Evidence from Germany", Finanzarchiv 56(3-4), pages 363-388.

Boadway, Robin, Maurice Marchand, and Pierre Pestieu (1994), "Towards a Theory of the Direct-Indirect Tax Mix", Journal of Public Economics 55, pages 71-88.

Corlett, W.J. and D.C. Hague (1953), "Complementarity and the Excess Burden of Taxation", 
Review of Economic Studies 10, pages 295-337.

Council of State Governments, The Book of the States, several years.

Cremer, Helmuth, Pierre Pestieu, and Jean-Charles Rochet (2001), "Direct Versus Indirect Taxation: The Design of the Tax Structured Revisited", International Economic Review, Vol. 42, No. 3, pages 781-799.

Diamond, Peter (1975), " A Many-Person Ramsey Rule", Journal of Public Economics 4, pages $335-342$.

Diamond, Peter A. and James A. Mirrlees (1971), "Optimal Taxation and Public Production I: Production Efficiency and II: Tax Rules", American Economic Review 61, pages 8-27 and 261-278. Gentry, William M. and Helen F. Ladd (1994), "State Tax Structure and Multiple Policy Objectives", National Tax Journal 47(4), pages 747-772.

Gordon, Roger H. and Soren Bo Nielsen (1997), "Tax Evasion in an Open Economy: ValueAdded vs. Income Taxation", Journal of Public Economics 66, pages 173-197.

Harberger, A. (1964), "Taxation, Resource Allocation, and Welfare", in : John Due (ed.), "The Role of Indirect and Direct Taxes in the Federal Revenue System", Princeton University Press, Princeton, New Jersey.

Harmon, Oskar R. and Rajiv Mallick (1994), "The Optimal State Tax Portfolio Model: An Extension", National Tax Journal 47, pages 395-401.

Heyndels, Bruno and Jef Vuchelen (1998), "Tax Mimicking Among Belgian Municipalities", National Tax Journal 51(1), pages 89-101.

Kesselman, Jonathan R. (1993), "Evasion Effects of Changing the Tax Mix", The Economic Record, Vol. 69, No.205, pages 131-148. 
Ladd, Helen F. (1992), "Mimicking of Local Tax Burdens among Neighboring Counties", Public Finance Quarterly 20(4), pages 450-467.

Mirrlees, James A. (1976), "Optimal Tax Theory: A Synthesis", Journal of Public Economics 6 , pages $327-358$.

Ramsey, F. P. (1927), "A Contribution to the Theory of Taxation", Economic Journal 37, pages 47-61.

Rork, Jonathan (2001), "Coveting Thy Neighbors' Tax Rates", Working Paper, Vassar College, New York.

Samuelson, Paul (1951), "Theory of Optimal Taxation", unpublished memorandum for the U.S. Treasury; published in: Journal of Public Economics 30, 1986, pages 137-143.

U.S. Department of Commerce, Bureau of the Census, "Statistical Abstract of the United States", several years.

White, Fred C. (1983), "Trade-Off in Growth and Stability in State Taxes", National Tax Journal 36, pages 103-114. 